\title{
Implantação de uma Proposta de Sistematização e Desenvolvimento da Educação Física do Ensino Médio
}

\author{
Claudio Kravchychyn* \\ Amauri Aparecido Bássoli de Oliveira ** \\ Sônia Maria Vicente Cardoso ***
}

\begin{abstract}
Resumo: Esta pesquisa de caráter de pesquisa-ação objetivou sistematizar os conteúdos da área e propor o seu desenvolvimento baseada nos pressupostos da pedagogia histórico-crítica. Foram sujeitos do estudo: gestoras, professor e estudantes do Ensino Médio de uma escola particular de Maringá-PR. As ações centraram-se em diagnóstico inicial, através de entrevistas com gestoras e professor e questionário aplicado aos alunos; montagem do currículo, planejamento e desenvolvimento das aulas durante um semestre; avaliação através de obsenvação, novas entrevistas e questionários. Como resultados, obteve-se a aprovação dos participantes ao novo formato, assim como a valorização do componente curricular para suas vidas.
\end{abstract}

Palavras-chave: Educação Física. Educação primária e secundária. Metodologia.

\section{INTRODUÇÃo}

Conforme a Lei de Diretrizes e Bases da Educação Nacional no 9394/96 (BRASIL, 1996), a Educação Física passou a ser um componente curricular integrado ao processo educacional, e não mais uma atividade paralela dentro da estrutura curricular da escola.

A disciplina, assim, obteve sua legalidade. Porém, ao longo do processo histórico da área, estabeleceram-se paradigmas que até hoje impedem sua legitimidade na escola. A direção que colocamos aqui é a de contribuir na busca de tal legitimidade.

"Professor Mestre do Centro Universitário de Maringá, PR, Brasil e Universidade do Oeste Paulista, Presidente Prudente, SP, Brasil. E-mail: claudiokrav@ wnet.com.br

"* Professor Doutor da Universidade Estadual de Maringá, PR, Brasil. E-mail: aaboliveira @uem.br "*** Mestre em Educação Professora Doutora da Universidade do Oeste Paulista, Presidente Prudente, SP, Brasil. E-mail: svcardoso@ superig.com.br 
Vários estudos apontam para uma resistência dos conceitos da "prática pela prática" e do improviso (MATTOS; NEIRA, 2000; GHIRALDELLI JUNIOR, 2003; OLIVEIRA, 2004; MOREIRA; CARBINATTO, 2006), que ainda caracterizam a Educação Física como uma atividade à margem do processo educacional.

Segundo Oliveira (2004), a Educação Física não possui - ao contrário de outras disciplinas - conteúdos sistematizados, que indicam o trabalho ao longo das séries escolares, gerando dúvidas, trabalhos desarticulados e sem sequiência lógica. No mesmo foco, Betti e Zuliani (2002, p. 77) apontam:

Os conteúdos devem adquirir complexidade crescente com o decorrer das séries, tanto do ponto de vista estritamente motor (habilidades básicas à combinação de habilidades, habilidades especializadas, etc.) como cognitivo (da simples informação à capacidade de análise, de crítica, etc.).

Desta forma, este estudo objetiva implantar e analisar uma proposta de sistematização de conteúdos para o Ensino Médio (OLIVEIRA, 2004). A escolha de metodologias condizentes com tal proposta e a sua aplicação efetiva a partir do diagnóstico de uma realidade passa a ser o nosso desafio.

Nossa proposta de trabalho foi apresentada à direção de uma escola particular da cidade de Maringá, Paraná (que abriga principalmente alunos de classe média), bem como ao docente da disciplina Educação Física. O acolhimento foi total.

\section{Caminho Metodológico}

A pesquisa seguiu os seguintes passos: conhecimento da realidade, adoção de uma metodologia de ensino, construção de um currículo, planejamento e aplicação (curso, unidades e aulas) e análise dos resultados.

Primeiro passo: a fim de conhecer a realidade da Educação Física na escola, realizamos entrevistas semi-estruturadas com a diretora, a coordenadora pedagógica e o docente de Educação Física

Movimento, Porto Alegre, v. 14, n. 02, p. 39-62, maio/agosto de 2008. 
do Ensino Médio, bem como aplicamos questionários compostos de questões abertas a todos os 57 alunos do Ensino Médio.

Segundo passo: quanto à metodologia de ensino, optamos pela proposta histórico-crítica, que preconiza “[...] a conversão do saber objetivo em saber escolar, de forma que se torne assimilável pelos alunos" (SAVIANI, 2003, p. 9) e que:

"[...] o novo indicador da aprendizagem escolar consistirá na demonstração do domínio teórico do conteúdo e no seu uso pelo aluno, em função das necessidades sociais a que deve responder. Esse procedimento implica um novo posicionamento, uma nova atitude do professor e dos alunos em relação ao conteúdo e à sociedade: o conhecimento escolar passa a ser teórico-prático. (GASPARIN, 2003, p. 2).

Terceiro passo: sob a proposta de sistematização de Oliveira (2004), foi construído um novo currículo da disciplina para atender às necessidades do processo, compartilhando o conceito de Sacristán (1998, p. 297), de elaboração de um "esquema apropriado de programação", estabelecido sobre três pontos capitais: a substantividade e ordenação dos conteúdos do currículo, a configuração das atividades mais adequadas para lograr o que se pretende e a capacidade de realizar esses planos dentro de determinadas condições de espaço, tempo, dotação de recursos, estrutura organizativa.

Quarto passo: as aulas, sob a nova perspectiva, foram elaboradas em conjunto (professor da disciplina e pesquisadores) e aplicadas pelo professor. Após observações, discussões e reflexões iniciais passamos a auxiliar diretamente nas aulas.

Quinto passo: a avaliação dos resultados aconteceu a partir de relatórios de atividades, novas entrevistas (gestoras e professor) e novos questionários (alunos) para verificar as mudanças ocorridas em conceitos, atitudes e conhecimentos adquiridos.

Os dados das entrevistas e questionários foram agrupados e analisados utilizando as indicações de Bardin (1995) para a análise de conteúdos.

Movimento, Porto Alegre, v. 14, n. 02, p. 39-62, maio/agosto de 2008. 
A ordem de trabalho delineada indica a caracterização de nosso estudo como pesquisa-ação, que para Barbier (1985, p. 38) "[...] é realizada em nível realista, acompanhada de reflexão autocrítica objetiva e de avaliação de resultados". Segundo Votre et al. (1983), tal modelo não faz diferença entre investigar e interferir na realidade, transformando o ato investigativo em processo de reflexão crítica e mudança.

\section{Diagnóstico InICIAL}

Nos relatos das gestoras (diretora e coordenadora pedagógica), do professor e dos alunos foram exteriorizadas experiências vividas dentro e fora da escola onde ocorreu a pesquisa. As gestoras e o professor tiveram experiências diversas - como alunos ou profissionais - que contribuíram para a formação do conceito sobre a disciplina. Entre os alunos, apenas 7\% estão nesta escola desde o início da vida escolar, sendo os demais oriundos de escolas públicas e particulares da mesma cidade, de outras cidades e Estados, o que contribui uma visão ampliada da realidade detectada.

Iniciamos a entrevista com as gestoras, solicitando que as mesmas fizessem um relato sobre suas experiências como alunas da disciplina Educação Física no Ensino Básico. Dos relatos, pudemos extrair duas experiências bastante significativas: da Diretora "[...] como aluna, a experiência que tive foi sempre em forma de competição. Atletismo e jogos. Não me lembro de ter estudado teoria na Educação Física" e da Coordenadora Pedagógica: "[...] a Educação Física se voltava para a melhora da forma física, só isso" .

Sobre a utilização dos conhecimentos adquiridos nas aulas, a Diretora relatou: "[...] pratico tênis, faço pilates. Das aulas de Educação Física escolar não utilizo nada" e a Coordenadora Pedagógica: "[...] não me lembro de nada que aprendi que use atualmente".

Solicitamos também suas percepções sobre a Educação Física de sua escola, seus professores, seus alunos. A Diretora ressaltou a falta de movimento: "[...] hoje cada vez mais crianças sofrem com o problema da obesidade, é muita televisão e computador". Já a

Movimento, Porto Alegre, v. 14, n. 02, p. 39-62, maio/agosto de 2008. 
Coordenadora Pedagógica elogiou a organização dos professores: "[...] trazem dentro do prazo o planejamento anual, a idéia geral, e depois detalham tudo nos bimestres".

As frases das gestoras, "pinçadas" das entrevistas, fomentaram nossas discussões, pois mostram uma Educação Física vista oficialmente como "atividade", bem como sendo importante o cumprimento das tarefas e prazos.

Devemos enfatizar a necessidade que a Educação Física tem enquanto geradora de conhecimentos, como ressalta Freire (1996, p. 76) "[...] a capacidade de aprender, não apenas para nos adaptar, mas para transformar a realidade, recriando-a". Ou seja, as condições de práticas que a escola oferece não são para sempre, é preciso preparar o aluno para a vida extra-escolar, na visão da disciplina como componente curricular.

$\mathrm{Na}$ entrevista com o professor, o mesmo mostrou-se interessado e motivado pela proposta. Contudo, também mostrou-se preocupado com a aceitação dos alunos e com o receio de não estar preparado para ministrar a disciplina sob o "novo" formato, ao se referir à visão dos alunos do Ensino Médio: "[...] a visão, em geral, é de que a Educação Física é o momento de sair da sala e ir para a quadra praticar esportes". Já sobre tentativas anteriores de mudança, relatou: "[...] não estava preparado, precisava de uma seqüência, um 'norte'. Os esportes dão segurança, mas sinto desconforto com isso".

Em consonância com as posições do professor, Oliveira (2000, p. 66), afirma: “[...] os profissionais da área não estão satisfeitos com seu desempenho e buscam novas opções e soluções para o desenvolvimento da Educação Física".

Ficou clara também a hegemonia dos conteúdos esportivos ministrados pelo professor. Mattos e Neira (2000, p. 19), referindose ao Ensino Médio, enfatizam que "[...] esse quadro, não raro, originado em etapas anteriores da escolarização, contribui muito para o afastamento do componente curricular do corpo pedagógico da escola".

O questionário inicial, aplicado aos alunos, tratou do entendimento dos mesmos sobre a Educação Física, com base em suas

Movimento, Porto Alegre, v. 14, n. 02, p. 39-62, maio/agosto de 2008. 
experiências anteriores. Foram abordados os conteúdos, a estrutura das aulas, sua importância e aproveitamento no cotidiano.

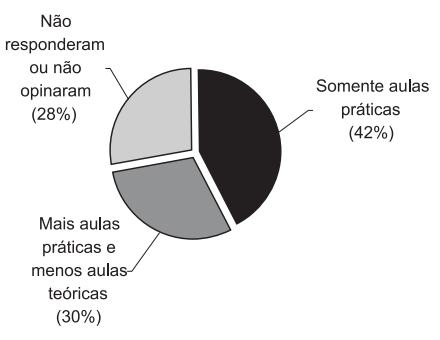

Figura 1 - Conteúdos estudados

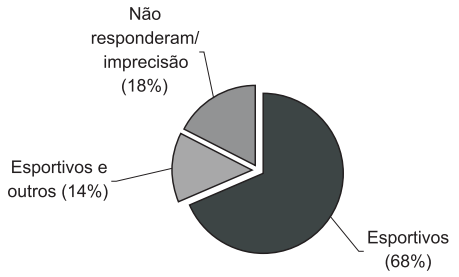

Figura 2 -Estruturação das aulas

A figura 1 representa um questionário sobre Conteúdos estudados, com perguntas abertas e a possibilidade para respostas imprecisas como "bons" e "chatos" e em branco (18\%). A grande maioria (68\%) coloca os esportes institucionalizados como único conteúdo. Os demais alunos (14\%) indicam também outros conteúdos, que parecem ter sido tratados esporadicamente, tais como: avaliações físicas, anatomia, drogas e alongamentos.

Já pela figura 2, sobre a Estruturação das aulas, podemos deduzir que parte dos alunos não entende o significado de "estruturação" ao não responder à questão (28\%). Entre os alunos que mencionaram apenas aulas práticas (42\%) encontramos afirmações sobre a atuação do professor como "bastante exercício em quadra", "sempre avaliava os conteúdos dos jogos" e "dava a bola e jogávamos". Entre os alunos que tiveram aulas teóricas (30\%) encontramos: "só alguns trabalhos", "xerox de regras e história dos esportes", "aulas teóricas sobre regras de esportes" e "avaliações, como peso e altura". Tais dados apontam para o descaso e o descompromisso dos professores com o processo ensino-aprendizagem.

Em seguida, procuramos saber se as aulas de Educação Física contribuíram na aquisição de hábitos ligados à atividade física e ao exercício físico.

Atividade física é definida por Caspersen et al. (1985, apud GUEDES; GUEDES, 1998, p. 11) como “[...] qualquer movimento corporal produzido pelos músculos esqueléticos, que resulta em gasto

Movimento, Porto Alegre, v. 14, n. 02, p. 39-62, maio/agosto de 2008. 
energético maior que os níveis de repouso". Já o "exercício físico" é subentendido como uma atividade física sistematizada, planejada e orientada (GUEDES; GUEDES, 1998; GONÇALVES; VILLARTA, 2004).

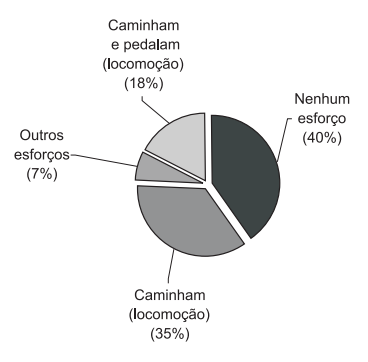

Figura 3 - Atividades físicas além das aulas

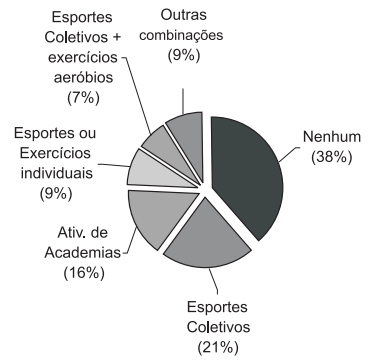

Figura 4 - Exercícios físicos além das aulas

Os dados apresentados na figura 3 apontam um grande percentual de inatividade física no dia-a-dia (40\%), e mostram atividades ligadas à locomoção e transporte (percentuais somados: 53\%). Poucos (7\%) relataram outros esforços, geralmente ligados à ajuda aos pais no trabalho e em tarefas domésticas. Preocupa-nos a tendência dos adolescentes à adoção de uma rotina de pouca atividade física.

Já a figura 4 traz a total falta de utilização dos conteúdos esportivos pela maioria (38\%). O índice de utilização dos esportes coletivos (21\%) pode ser considerado baixo, por ser o conteúdo mais vivenciado. Chama atenção a prática de atividades de academia (16\%), não incluídas no rol dos conteúdos estudados. As demais formas de exercícios (individuais, coletivos e aeróbios aliados a outros) somaram $25 \%$ dos depoimentos.

Cabe aqui a afirmação de Mattos e Neira (2000, p. 17): “A conquista das competências propostas para o Ensino Médio na área específica da Educação Física depende de uma prática educativa que tenha como eixo a formação de um cidadão autônomo e participativo".

O diagnóstico inicial pode ser assim sintetizado: as gestoras e os alunos não desvalorizavam a Educação Física, mas a entendiam como "atividade", o que era compreensível, uma vez que a disciplina

Movimento, Porto Alegre, v. 14, n. 02, p. 39-62, maio/agosto de 2008. 
não parece ter gerado conhecimentos e estímulos para a prática de atividades e exercícios físicos. Por sua vez, o professor reconhecia a necessidade de legitimar a Educação Física como componente curricular, sentia desconforto, queria, mas buscava "como" mudar e temia a resistência dos alunos.

\section{As Ações}

A sistematização da Educação Física escolar idealizada por Oliveira (2004) é uma proposta de organização curricular, conforme mostra o quadro abaixo.

\begin{tabular}{|l|l|}
\hline Núcleos & Conteúdos Básicos \\
\hline $\begin{array}{l}\text { a) O movimento em construção e } \\
\text { estruturação }\end{array}$ & $\begin{array}{l}\text { Habilidades motoras de base (locomotoras, não locomotoras, manipu- } \\
\text { lativas, coordenação viso-motora), esquema corporal, percepção } \\
\text { corporal. }\end{array}$ \\
\hline $\begin{array}{l}\text { b) O movimento nas manifestações } \\
\text { lúdicas e esportivas }\end{array}$ & $\begin{array}{l}\text { Jogos (motores, sensoriais, criativos, intelectivos e pré-desportivos); } \\
\text { esporte institucionalizado (basquetebol, voleibol, handebol, atletismo, } \\
\text { futsal, ciclismo e outros), e esportes alternativos (capoeira, escaladas, } \\
\text { caminhadas, passeios, bets, malha, peteca e outros). }\end{array}$ \\
\hline c) O movimento em expressão e ritmo & Ginástica, dança, brinquedos cantados, cantigas de roda e outros. \\
\hline d) O movimento e a saúde & $\begin{array}{l}\text { Higiene e primeiros socorros, ergonomia, bases anátomo-fisiológicas do } \\
\text { corpo humano, bases nutricionais, aspectos básicos da metodologia do } \\
\text { treinamento, avaliações do crescimento, desenvolvimento, composição } \\
\text { corporal e aptidão fisica. }\end{array}$ \\
\hline
\end{tabular}

Quadro 1 - Organização dos núcleos temáticos e seus respectivos conteúdos Fonte: Oliveira (2004, p. 30)

Sob esta idealização, todos os núcleos estão presentes em maior ou menor grau em todas as séries. Para o Ensino Médio, a proposta acontece da seguinte maneira:

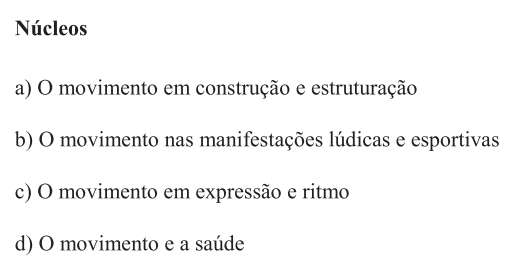

\begin{tabular}{|c|c|c|}
\hline $\mathbf{1}^{\text {a }}$. Série & $\mathbf{2}^{\mathbf{a}}$. série & $\mathbf{3}^{\mathbf{a}}$. série \\
\hline $10 \%$ & $5 \%$ & $5 \%$ \\
\hline $45 \%$ & $40 \%$ & $40 \%$ \\
\hline $10 \%$ & $15 \%$ & $15 \%$ \\
\hline $35 \%$ & $40 \%$ & $40 \%$ \\
\hline
\end{tabular}

Quadro 2 - Proposta de organização dos conteúdos ao longo das séries do Ensino Médio Fonte: Oliveira (2004, p. 30)

Movimento, Porto Alegre, v. 14, n. 02, p. 39-62, maio/agosto de 2008. 
Para distribuição percentual dos núcleos, Oliveira (2004, p. 31) afirma que "foram levados em consideração, além dos componentes, os interesses que os alunos manifestam ao longo da vida escolar".

O modelo de pesquisa-ação escolhido não nos caracterizou apenas como observadores, que apontam erros e acertos, fazem suas considerações e se retiram (DAOLIO, 1995), mas como co-participantes e mais do que isso, co-responsáveis.

O início do nosso trabalho foi centrado na informação e conscientização da comunidade escolar sobre a nova proposta e como pretendíamos fazê-la acontecer. Professores de Educação Física de outros níveis, professores das demais disciplinas e alunos foram colocados a par da "nova realidade" e convidados a participar do processo.

Embora tenhamos centrado o presente estudo no Ensino Médio, o planejamento e as ações foram executados em todos os níveis de ensino da escola. Na primeira reunião de planejamento, cada professor escreveu os conteúdos a ministrar em cartazes, divididos inicialmente por ciclos: jardim I, II e III (Educação Infantil) $1^{\mathrm{a}}$ a $4^{\mathrm{a}}$ série (Ensino Fundamental), $5^{\mathrm{a}}$ a $8^{\mathrm{a}}$ série (Ensino Fundamental) e $1^{\mathrm{a}}$ a $3^{\mathrm{a}}$ série (Ensino Médio). Depois, os conteúdos foram colocados mediante discussões - dentro das séries e núcleos (unidades), conforme os percentuais estabelecidos. Foram necessárias três reuniões para a finalização do planejamento curricular, que foi baseado na realidade local, fator fundamental diante da proposta e da metodologia de trabalho adotadas.

Os planos de aula foram construídos em conjunto (professor do Ensino Médio e pesquisadores). A reflexão sobre as aulas foi uma constante durante todo o processo.

Para descrição das aulas, utilizamos um roteiro baseado na pedagogia histórico-crítica e organizado por Gasparin (2003): prática social inicial (o que alunos e professor já sabem), problematização (explicitação dos principais problemas da prática social), instrumentalização (ações didático-pedagógicas para a aprendizagem), catarse (expressão elaborada da nova forma de entender a

Movimento, Porto Alegre, v. 14, n. 02, p. 39-62, maio/agosto de 2008. 
prática social) e prática social final (nova proposta de ação a partir do conteúdo aprendido).

Apresentamos, abaixo, uma aula relatada, para melhor visualização.

- Turmas: $1^{\mathrm{a}}, 2^{\mathrm{a}}$ e $3^{\mathrm{a}}$ séries do Ensino Médio (com problematizações específicas para cada turma);

· Tema: “A musculação, suas variáveis e suas possibilidades”;

- Local: quadra de esportes;

- Objetivo: proporcionar conhecimentos e experiências sobre exercícios com peso, seus riscos e benefícios e variações em relação à aplicação de sobrecargas;

- Material: quadro de giz (portátil), barras, anilhas, $\mathrm{CD}$, aparelho de som;

- Prática social inicial: o tema foi apresentado pelo professor, com o mesmo atribuindo importância à aula pela procura crescente de atividades de academia envolvendo exercícios com pesos por parte de adolescentes;

- Problematização geral: os questionamentos "quem de vocês já praticou ou pratica exercícios com peso?" e "com que objetivo?" nortearam a pequena discussão. Nas três turmas havia alunos com experiência. Como esperado, os meninos demonstraram interesse por maior hipertrofia muscular e as meninas por emagrecimento e menor hipertrofia. Como transição para a prática (instrumentalização), o professor antecipou as atividades, que abordariam os interesses detectados: exercícios sob predominância das sobrecargas metabólica (menor carga e mais repetições) e tensional (maior carga e menos repetições).

- Problematizações específicas (relacionadas a outros conteúdos de cada série): $1^{\mathrm{a}}$ série: tipos de fibra muscular; $2^{\mathrm{a}}$ série: estímulo, adaptação, intensidade e volume; $3^{\mathrm{a}}$ série: organização de planos de treinamento.

Instrumentalização: a prática foi ministrada em conjunto, pelo pesquisador $\left(1^{a}\right.$ parte - sobrecarga metabólica) e pelo professor da turma ( $2^{\mathrm{a}}$ parte - sobrecarga tensional). Primeira parte: alunos

Movimento, Porto Alegre, v. 14, n. 02, p. 39-62, maio/agosto de 2008. 
dispostos na quadra de frente para o professor, tendo em mãos barras montadas com baixas cargas. Após a explicação de exercícios básicos, foi realizado o aquecimento com música, envolvendo repetições ritmadas dos exercícios. Em seguida, também com música, foram realizados exercícios para os membros inferiores por cerca de 5 minutos ( 3 pausas). Idem para os membros superiores. Segunda parte: o professor solicitou que um aluno (já praticante de musculação) viesse à frente para executar a "rosca bíceps", em oito repetições com o máximo de peso para tal volume. Após, em trios homogêneos (peso, altura e gênero) com os devidos cuidados, os alunos puderam experimentar a mesma situação.

- Catarse: a musculação tradicional e suas variáveis (ginástica localizada, Body Pump, hidroginástica e outras) são modalidades de exercícios procuradas por pessoas de várias idades, em busca de saúde e estética. Foi enfatizado que conhecimento prévio adquirido nas aulas de Educação Física pode evitar riscos na prática e na escolha de um bom profissional para a orientação fora da escola.

- Prática social final: Os alunos foram solicitados a refletir sobre o interesse pela estética corporal demonstrado na problematização da aula, e também sobre como a falta ou o excesso de exercícios com pesos poderia afetar sua saúde e suas vidas. As problematizações específicas de cada série foram também refletidas, a fim de gerar interesse por outros conteúdos a serem trabalhados.

A avaliação bimestral nos anos anteriores era composta de uma prova prática (fundamentos dos esportes), uma prova teórica (regras dos esportes e temas relacionados à saúde, estudados em forma de textos) e um conceito por participação.

Compartilhamos do conceito de Hoffmann (2004), que aponta a avaliação como um processo dinâmico que acompanha o processo de construção do conhecimento.

Embora limitado pela falta de conteúdos e refletindo um modelo tecnicista já superado, o sistema de avaliação anterior contempla aspectos - mesmo que poucos - formativos e informativos, visto que eram avaliados itens de desempenho de tarefas (prova prática) e de conhecimentos teóricos adquiridos no bimestre (prova teórica).

Movimento, Porto Alegre, v. 14, n. 02, p. 39-62, maio/agosto de 2008. 
Assim sendo, quanto à forma de avaliação não foi promovida uma "grande revolução", mas podemos afirmar que os passos iniciais foram dados. Os novos conteúdos e a nova metodologia de ensino trataram de constituir-se em diferencial.

Mesmo nas práticas esportivas havia um tema adjunto a ser trabalhado. Tais práticas passaram, pois, a constituir-se em meio para estudo de temas diversos. O "conceito por participação" foi fortalecido por trabalhos em sala e para casa, valendo nota. A pesquisa foi - mesmo que de forma tímida - instituída. O caderno multimatérias teve a parte da Educação Física efetivamente utilizada.

A avaliação será otimizada na medida em que o processo de sistematização se consolide. Para tanto, o trinômio ação-reflexãoação deve ser continuamente exercitado.

\section{Os Resultados}

Após um semestre de trabalho, apesar de dificuldades enfrentadas (seleção de conteúdos, preparação de aulas, mudanças metodológicas e resistência dos alunos, entre outras), percebemos consideráveis avanços através de observações e participações. Contudo, somente nossos olhares não seriam suficientes para apresentar conclusões.

Desta forma, foi preciso novamente entrevistar e aplicar questionários a todos que estiveram envolvidos neste processo de re-configuração da disciplina, que em maior ou menor grau sofreram alguns "choques" pela quebra de antigos paradigmas.

A entrevista final com as gestoras foi mais fácil e agradável, pois já éramos vistos como integrantes da comunidade escolar. Nossos novos questionamentos foram centrados nas discussões sobre o "novo formato" da Educação Física da escola.

Embora as funções do dia-a-dia impeçam um olhar mais direto da diretora e da coordenadora pedagógica para as aulas, ninguém melhor para apontar a percepção geral da comunidade escolar do que elas, que geralmente recebem e absorvem reclamações.

Movimento, Porto Alegre, v. 14, n. 02, p. 39-62, maio/agosto de 2008. 
Solicitamos às gestoras que expusessem os fatores que mais lhes chamaram a atenção durante o processo, e selecionamos os trechos mais significativos das falas.

A diretora observou: "[...] antes, os alunos iam direto para a quadra. Atualmente, eles aguardam o professor na sala, sabem que a aula pode ser prática ou teórica. A inclusão de conteúdos além dos jogos deu nova característica à disciplina". Já a coordenadora considerou: "[...] as provas de Educação Física mudaram, eram compostas apenas de regras dos esportes. Nas últimas avaliações encontramos questões sobre nutrição, contração muscular, qualidades físicas. A avaliação melhorou muito".

A aprovação das gestoras à "nova" Educação Física é evidente. Porém, vale relembrar o receio e certo ceticismo da diretora quando da entrevista inicial: "[...] ao ver aquele planejamento na parede, pensei: meu Deus, eles abraçaram mesmo a causa".

Quanto ao receio de rejeição do alunado, a coordenadora pedagógica disse: "[...] pensei que as aulas ficariam menos prazerosas, fiquei preparada para uma 'chuva de reclamações'. Não houve uma sequer".

Assim, percebemos uma mudança na visão sobre Educação Física por parte da diretora e da coordenadora pedagógica. Frases como a da Diretora: "[...] a Educação Física é vista como uma matéria necessária, que tem profundidade, o aluno tem conhecimentos a adquirir" e da Coordenadora "[...] os alunos estão aprendendo a se cuidar para toda a vida, a desenvolverem suas aptidões físicas, eu acredito que isso vai mudar a vida dos alunos", sintetizam a nova percepção das gestoras.

$\mathrm{Na}$ entrevista final com o professor, solicitamos que o mesmo expusesse suas dificuldades durante o processo. Sobre o planejamento, assim se posicionou:

[...] a maior dificuldade foi seguir uma lógica. São quatro grandes núcleos, trabalhamos por blocos. Antes, em cada bimestre trabalhávamos um esporte diferente, era obviamente mais fácil. Não sabemos se a sequiência que elaboramos é a melhor, mas com

Movimento, Porto Alegre, v. 14, n. 02, p. 39-62, maio/agosto de 2008. 
certeza a cada ano o planejamento estará melhor, pois aprendemos com os erros (PROFESSOR).

Oliveira (2004) considera que o caminho para a adequada organização dos conteúdos da área é longo e trabalhoso, mas entende que sem estudo e esforço pouco se poderá alcançar no sentido de se legitimar a Educação Física no sistema educacional.

Quanto ao planejamento e aplicação das aulas, o professor apontou como maior dificuldade a necessidade de estudo: “[...] não basta o conhecimento genérico, do dia-a-dia, para entrarmos em sala de aula e conquistarmos os alunos" e "o domínio dos conteúdos e a metodologia aplicada fazem a diferença".

O professor pareceu - mesmo reconhecendo dificuldades e limitações - ter vencido a sensação de desconforto que tinha no início do processo, quando a disciplina, segundo os relatos do mesmo, era caracterizada como "atividade".

[...] a Educação Física era destituída de um conhecimento sistematizado a ser oferecido aos alunos, não passando de uma prática assistemática, sem uma organização interna, enfim, um fazer por fazer. Como "atividade", aparecia com "baixo status" na hierarquia dos saberes escolares, configurando-se como um mero apêndice na escola, sem maiores pretensões (SOUSA; VAGO, 1999, apud AYOUB, 2003, p. 111).

Perguntado sobre a utilização concreta dos novos conteúdos trabalhados na disciplina, o professor respondeu: "Eu acredito que já houve uma mexida no dia-a-dia dos alunos, apesar de ser uma percepção sem dados mais concretos".

Quanto à superação da resistência dos alunos às mudanças, declarou:

[...] os pequenos grupos que exigiam um determinado tipo de aula foram se integrando e cedendo às exigências da disciplina. Foi vencida a primeira barreira. Acho que a aula deve ser um momento agradável, o que não significa fazer só o que os alunos querem (PROFESSOR).

Movimento, Porto Alegre, v. 14, n. 02, p. 39-62, maio/agosto de 2008. 
Conforme Costa (1997 apud DARIDO et al., 1999, p. 141), "[...] é comum entre os alunos um primeiro discurso pautado em não gostar da atividade, e transformar estas opiniões se constitui no maior desafio para os professores do Ensino Médio".

O professor, em sua fala, deixa claro que se sente bem dentro do novo contexto, e visualiza boas perspectivas: "[...] foi um pequeno avanço até agora, mas ele sem dúvida ocorreu. No próximo ano entraremos mais forte, e assim a cada ano".

A motivação demonstrada pelo professor nos remete à seguinte contextualização de Rangel-Betti (2001, p. 30):

Os dias atuais demonstram que não há mais espaço para os acomodados, os desmoti-vados, os que simplesmente reproduzem e não transformam. Apenas um profissional reflexivo, ao meu entender, será capaz de ultrapassar as fronteiras e obstáculos que surgem em todos os instantes.

Um longo caminho se apresenta ao nosso professor, que não se apresentaria se o mesmo ficasse "parado no tempo", conforme sua própria expressão.

Após a nova experiência com a Educação Física, proporcionamos aos alunos a oportunidade de expressão através de um questionário final. Foi um momento, sobretudo, de reflexão e análise das ações realizadas.

$$
\begin{aligned}
& \text { Uma ação concreta, a partir do momento em que o } \\
& \text { educando atingiu o nível do concreto pensado, é } \\
& \text { também todo o processo mental que possibilita } \\
& \text { análise e compreensão mais amplas e críticas da } \\
& \text { realidade, determinando uma nova maneira de } \\
& \text { pensar, de entender e julgar os fatos, as idéias. É } \\
& \text { uma nova ação mental (GASPARIN, 2003, p. 144). }
\end{aligned}
$$

Responderam às questões os mesmos alunos que participaram do questionário inicial. Nesta segunda incursão, procuramos coletar dados sobre o interesse pelos novos conteúdos, a motivação gerada pela metodologia de ensino utilizada, a utilização dos conhecimentos no cotidiano e o nível de satisfação com a "nova" Educação Física.

Movimento, Porto Alegre, v. 14, n. 02, p. 39-62, maio/agosto de 2008. 


\section{Astigor Originais}

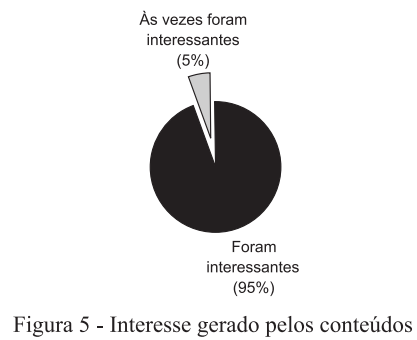

Claudio Kravchychyn, et al.

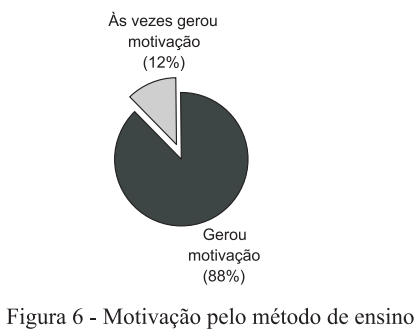

Os dados apresentados na figura 5 confirmam que os alunos se interessam por conteúdos que dizem respeito à sua realidade, seu cotidiano, conforme apresentado pela literatura da Educação Física escolar (MATTOS; NEIRA, 2000; OLIVEIRA, 2004).

Nenhum aluno considerou os conteúdos trabalhados no semestre como desinteressantes, poucos alunos relataram às vezes terem sido interessantes (5\%) e na opinião da maioria absoluta (95\%) os conteúdos foram interessantes. Vejamos algumas justificativas: “[...] além da prática de esportes, foram transmitidos conhecimentos de nutrição, musculação, dança e ginástica", "[...] fizemos coisas diferentes, saímos da rotina", "[...] conhecimentos para cuidar melhor do corpo, da saúde".

A figura 6 mostra uma grande diferença observada quanto à motivação gerada pelo método de ensino aplicado (às vezes gerou motivação: $12 \%$; e gerou motivação: $88 \%$ ). Algumas expressões sobre a atuação do professor: "conteúdos ensinados de forma divertida, dinâmica, atrativa, animada", "relacionou teoria e prática", "o professor interagiu com os alunos", "prendeu a atenção e despertou a curiosidade".

Os percentuais e os depoimentos dos alunos apontam para um grande avanço, pois a metodologia anterior utilizada pelo professor possuía características claramente diretivas, conforme declarava: "a grande maioria das aulas acaba sendo através de comando, não fugindo muito" e "nas aulas diretivas consigo dominar melhor a turma".

Movimento, Porto Alegre, v. 14, n. 02, p. 39-62, maio/agosto de 2008. 
Para Gasparin (2003), a problematização é o elemento-chave na transição entre a prática e a teoria. Na maioria das aulas, houve a possibilidade de se contextualizar e problematizar os conteúdos. Algumas vezes (no início) isso não ocorreu, provavelmente pela falta de hábito de participação e co-responsabilidade por parte dos alunos.

Procuramos, por último, verificar se os alunos visualizam o aproveitamento dos conteúdos no seu dia-a-dia e seu nível de satisfação com as mudanças na disciplina.

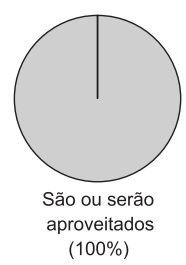

Figura 7 - Aproveitamento dos conteúdos

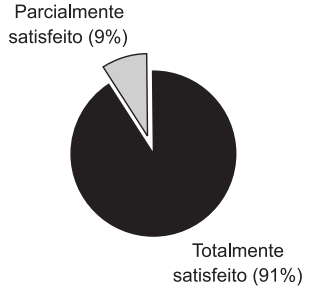

Figura 8 - Nível de satisfação dos alunos

Como visto na figura 7 , todos os alunos declararam que vão utilizar ou que já estão utilizando os conhecimentos gerados pelos conteúdos estudados.

A maioria dos discentes apresentou justificativas que apontam para uma visão abrangente da utilização dos conteúdos: "saber quando, como e porque nos exercitarmos", "aprendi como emagrecer e cuidar do meu corpo", "antes eu não fazia nada. Vou me exercitar a partir de agora", "conhecemos novas técnicas de exercícios", "as aulas teóricas, a musculação, a dança, vou usar tudo", "posso passar adiante meus conhecimentos, ajudando meus familiares e amigos".

Houve uma sensível melhora na expectativa de utilização imediata e futura dos conteúdos. Porém, o fator mais gratificante fica a cargo da consciência adquirida quanto à importância dos conhecimentos ligados ao movimento humano.

Já na figura 8, observamos que o nível de satisfação dos nossos alunos com a Educação Física é alto: 91\%, contra 9\% de alunos parcialmente satisfeitos. Nenhum aluno se mostrou insatisfeito com a nova forma de condução da disciplina.

Movimento, Porto Alegre, v. 14, n. 02, p. 39-62, maio/agosto de 2008. 
Algumas justificativas para "totalmente satisfeito": "alia teoria e prática", "cada dia melhor, coisas novas, atividades diferentes", "aulas divertidas", "100\%, estou adorando as novas aulas", "em outros colégios não tem esses conteúdos", "não gostava muito de jogar só bola", "as novas aulas motivaram quem não curtia a Educação Física", "aprendo mais do que antigamente, as aulas são mais motivantes".

Justificativas para "parcialmente satisfeito": "tem o lado positivo, mas eu gostava do outro jeito", "deveria ter menos aulas teóricas", "aulas diferentes, sim, mas sem teoria", "está bom, mas acho melhor só prática, mesmo sem aprender nada".

Este último item nos remete ao caminho percorrido desde o início desta pesquisa, pois quando aplicamos o primeiro questionário aos alunos nos sentimos um pouco "invasores". Ao final da experiência, somos participantes de fato. Já os alunos foram chamados a opinar, criticar, sugerir, reivindicar, e o fizeram como quem não apenas vivencia atividades, mas compromete-se com o processo ensino-aprendizagem.

\section{Considerações Finais e Conclusões}

No início do percurso, não conseguimos vislumbrar sob quais condições chegaríamos ao final. As estratégias metodológicas adotadas apontavam para grandes desafios, pois o modelo de pesquisaação nos traz a possibilidade de intervir no ambiente pesquisado. Apesar de conhecermos bem a realidade nacional da Educação Física (tão discutida, tão contestada, tão pouco modificada) nos encontrávamos numa espécie de "hora da verdade". O trabalho junto a adolescentes - que estão numa fase da vida marcada pela crítica e exigência - também nos preocupava, uma vez que os mesmos iriam vivenciar um processo de mudança radical: uma re-configuração da disciplina, visando sua legitimação como componente curricular.

O planejamento realizado seguiu rigorosamente os princípios didáticos e metodológicos preconizados pela proposta de Oliveira

Movimento, Porto Alegre, v. 14, n. 02, p. 39-62, maio/agosto de 2008. 
(2004), recebendo ainda características da pedagogia históricocrítica, baseada na realidade cotidiana dos alunos.

Os conteúdos atribuídos a cada série e o trabalho junto às turmas estiveram sempre de acordo com o planejamento. Em alguns momentos (especialmente no início do processo), o professor precisou "negociar" algumas aulas mais descompromissadas por algumas extremamente necessárias ao cumprimento dos objetivos propostos.

Aos poucos, as resistências foram superadas e as características formativas e informativas da disciplina passaram a se desenvolver com harmonia. A variedade de conteúdos tratou de sanar alguns aspectos motivacionais prejudicados pela permanência em sala para aulas teóricas. A problematização foi quase sempre possível, especialmente no trabalho de temas próximos da realidade dos adolescentes.

As entrevistas e questionários finais mostraram as gestoras, $o$ professor da disciplina e os alunos modificados em seus conceitos sobre a Educação Física.

No início do processo, a diretora e a coordenadora pedagógica externavam conceitos sobre a Educação Física escolar que mantinham a disciplina na condição de atividade paralela, sem maiores funções educacionais. Não podemos culpá-las pela forma de enxergar a Educação Física naquele momento, pois construíram essas imagens com suas histórias de vida e relação com a área. Da mesma forma, o próprio docente se mostrava desconfortável com a "prática pela prática" que caracterizava a disciplina.

Acreditamos fortemente que as mudanças significativas ocorrem "de dentro para fora". Se nós, professores de Educação Física, não assumimos nossas dificuldades e limitações, não procuramos soluções e não temos iniciativa para mudar, como podemos esperar reconhecimento de outras áreas e da comunidade escolar em geral?

Assim, planejamos, ministramos as aulas, refletimos, refizemos. Trilhamos, pois, o caminho proposto, fazendo da dificuldade nossa motivação.

Como visto nas entrevistas finais, as gestoras reconheceram a Educação Física como componente curricular, ao ressaltar características formativas e informativas da disciplina em seus depoimentos.

Movimento, Porto Alegre, v. 14, n. 02, p. 39-62, maio/agosto de 2008. 
Quanto ao professor, a entrevista final mostrou um profissional confiante e estimulado a continuar desenvolvendo o processo. Percebemos a superação do desconforto inicial e das pressões do início do semestre. Apesar de sua simplicidade e discrição, podemos perceber a satisfação em poder superar suas dificuldades.

Os alunos, que no início precisavam ser "conquistados", ao final do semestre não apresentaram rejeição à disciplina, com índice de satisfação plena de $91 \%$, o que mostra a formação de um novo conceito sobre a Educação Física por parte dos mesmos. Isso tudo levando em consideração que a disciplina passou a ser mais trabalhosa (foram exigidos trabalhos e tarefas em sala e para casa e mais conteúdos para provas teóricas).

A possibilidade de opinar, os acordos firmados com o professor, o estímulo à co-participação e os conhecimentos adquiridos parecem ter promovido também uma melhora na consciência crítica dos alunos, fato facilmente observável ao compararmos as respostas - e interesse em responder as questões - dos questionários iniciais e finais.

A partir das considerações realizadas e, com a finalidade de atender à solicitação do objetivo do presente estudo, podemos realizar nossas conclusões finais.

A disciplina Educação Física, planejada e ministrada nos moldes descritos na presente pesquisa, atende às exigências para ser não só considerada, mas efetivamente reconhecida pela comunidade escolar como componente curricular do sistema educacional.

A proposta de Oliveira (2004) foi satisfatoriamente aplicada, desde o planejamento realizado até o trabalho dos conteúdos em aula, por terem sido os temas adequados à realidade da escola.

As ações didático-pedagógicas se desenvolveram satisfatoriamente, o método de ensino foi considerado motivante e eficaz, o aprendizado dos conteúdos e a relação dos mesmos com o dia-a-dia dos alunos foi plena, segundo a opinião dos alunos.

A proposta metodológica de nossa pesquisa envolveu uma gama diversificada de procedimentos por meio dos quais os dados foram

Movimento, Porto Alegre, v. 14, n. 02, p. 39-62, maio/agosto de 2008. 
coletados, analisados, apresentados e discutidos. Desta forma, cabe aqui enfatizar que a limitação do estudo se apresenta na impossibilidade de se generalizar tais dados, devido à especificidade do tipo de pesquisa e da realidade estudada.

Consideramos, contudo, que ações nesse sentido devem ser estimuladas por vários motivos: pela quebra de paradigmas históricos que impedem a legitimação da Educação Física no ambiente escolar; pela inserção efetiva da disciplina no processo de ensino; pela contribuição substancial para avanços na área; pela conseqüente valorização da disciplina e dos profissionais de Educação Física atuantes no sistema educacional; por fim e, sobretudo, pela significância da ação educativa de transformar para melhor a vida das pessoas.

Movimento, Porto Alegre, v. 14, n. 02, p. 39-62, maio/agosto de 2008. 


\begin{abstract}
Implantation of a proposal for systematization and development of physical education on high school Abstract: This paper on features of research - action aimed at systematizing the content of the area and offered for discussion its development based on presupposed of the historic critical Pedagogy. Directors, teachers and students from a private high school in Maringa-Parana were samples of study. The actions were placed in a first diagnosis through interview with directors and teachers, questionnaire applied to students; elaboration of résumé, class planning and development during one semester; assessment through observation, new interviews and questionnaires. As a result, the approval of participants to the new arrangement was achieved, as well as, the appreciation of curricular component to their lives.

Key-words: Physical Education. Education, Primary and secondary. Methodology.
\end{abstract}

Implantación de una propuesta de sistematización y desarollo de la educación física de la enseñanza media

Resumen: Esta pesquisa de característica de pesquisaacción se objetivó sistematizar los contenidos del área y proponer su desarollo basada en los presupuestos de la pedagogia histórico-crítica. Fueron sujetos del estudio: gestoras, profesor y estudiantes de la enseñanza media de una escuela privada de Maringá-PR. Lãs acciones se centraron en diagnostico inicial, por medio de entrevista con gestoras y profesor y cuestionario aplicado a los alumnos; montaje del curriculo, planeamiento y desarrollo de las clases durante un semestre; evaluación por medio de observación, nuevas entrevistas y cuestionarios. Como resultado se obtuvo la aprobación de los participantes al nuevo formato, así como la valoración del componente curricular para sus vidas.

Palabras-claves: Educación Física. Educación primária y secundaria. Metodología.

\title{
REFERÊNCIAS
}

AYOUB, Eliana. Educação Física escolar: compromissos e desafios. Motus Corporis, Rio de Janeiro, v. 10, n. 1, p. 106-117, maio 2003.

Movimento, Porto Alegre, v. 14, n. 02, p. 39-62, maio/agosto de 2008. 
BARBIER, René. A pesquisa-ação na instituição educativa. Rio de Janeiro: Jorge Zahar, 1985.

BARDIN, Laurence. Análise de Conteúdo. Lisboa: Edições 70, 1995.

BETTI, Mauro; ZULIANI, Luiz Roberto. Educação Física Escolar: uma proposta de diretrizes pedagógicas. Revista Mackenzie de Educação Física e Esporte, São Paulo, v. 1, n. 1, p. 73-81, 2002.

BRASIL. Ministério da Educação e do Desporto. Lei de Diretrizes e Bases da Educação Nacional (Lei no. 9394/96). Brasília, 1996.

BRASIL. Secretaria de Educação Fundamental. Parâmetros Curriculares Nacionais - Educação Física: Educação Física/Secretaria de Educação Fundamental. Brasília, DF: MEC/SEF, 1997.

DAOLIO, Jocimar. Da cultura do corpo. Campinas: Papirus, 1995.

DARIDO, Suraya Cristina; GALVÃO, Zenaide; FERREIRA, Lilian Aparecida; FIORIN, Giovanna. Educação Física no Ensino Médio: reflexões e ações. Motriz, Rio Claro, v. 5, n. 2, p. 138-145, dez/1999.

FREIRE, Paulo. Pedagogia da autonomia: saberes necessários à prática educativa. Rio de Janeiro: Paz e Terra, 1996.

GASPARIN, João Luiz. Uma didática para a pedagogia Histórico-Crítica. Campinas, SP: Autores Associados, 2003.

GHIRALDELLI JUNIOR, Paulo. Educação Física Progressista: a pedagogia crítico-social dos conteúdos e da Educação Física Brasileira. São Paulo: Loyola, 2003.

GONÇALVES, Aguinaldo; VILLARTA, Roberto. Qualidade de vida e atividade física: explorando teoria e prática. Barueri: Manole, 2004.

GUEDES, Dartagnan Pinto; GUEDES, Joana Elisabete Ribeiro Pinto. Exercício Físico na Promoção da Saúde. Londrina: Midiograf, 1998.

HOFFMANN, Jussara. Avaliar para promover: as setas do caminho. Porto Alegre: Mediação, 2004.

MATTOS, Mauro Gomes; NEIRA, Marcos Garcia. Educação Física na Adolescência: construindo o conhecimento na escola. São Paulo: Phorte, 2000.

MOREIRA, Wagner Wey; CARBINATTO, Michele Viviene. Bases epistemológicas, a Educação Física e o esporte: possibilidades. Revista Brasileira de Educação Física e Esporte, São Paulo, v. 20, p. 129-130, 2006.

OLIVEIRA, Amauri Aparecido Bássoli. Mudanças metodológicas no cotidiano escolar: uma experiência com a metodologia do "ensino aberto" no Ensino Médio noturno. Corpoconsciência, Santo André, v. 5, p. 65-79, $1^{\circ}$ sem. 2000.

Movimento, Porto Alegre, v. 14, n. 02, p. 39-62, maio/agosto de 2008. 
62 Artifor Orifinais Claudio Kravchychyn, Amauri Aparecido...

Planejando a Educação Física Escolar. In: VIEIRA, J. L. L. (Org). Educação Física e Esportes: estudos e proposições. Maringá: EDUEM, 2004. p. 25-55.

RANGEL-BETTI, Irene Conceição. Educação Física no Ensino Médio: analisando um processo de aprendizagem profissional. Motriz, Rio Claro, v. 7, n. 1, p. 17-22, Jan./Jun. 2001.

SACRISTÁN, José Gimeno. 0 currículo: uma reflexão sobre a prática. Porto Alegre: Artmed, 1998.

SAVIANI, Demerval. Pedagogia Histórico-Crítica. Campinas: Autores Associados, 2003.

VOTRE, Sebastião José; BOCCARDO, Ludmila. Mourão; FERREIRA NETO, Amarílio. Pesquisa em Educação Física. Vitória: UFES, 1993. 